\title{
Profundidade de plantio e dominância apical na estaquia de pitaia vermelha
}

\section{Depth of planting and apical dominance on cuttings of red pitaya}

\author{
Virna Braga Marques ${ }^{1}$; Rodrigo Amato Moreira ${ }^{1 *}$; José Darlan Ramos²; \\ Neimar Arcanjo de Araújo ${ }^{3}$; Maria do Céu Monteiro da $\mathrm{Cruz}^{4}$
}

\begin{abstract}
Resumo
O trabalho foi conduzido com o objetivo de avaliar os efeitos da profundidade de plantio e da quebra de dominância apical na estaquia de pitaia vermelha Hylocereus undatus (Haw.) Britton \& Rose. O experimento foi instalado no delineamento em blocos casualizados, com quatro repetições no esquema fatorial 2x3, sendo dois tipos de estacas (com e sem dominância apical), estacas não seccionadas e seccionadas a $5 \mathrm{~cm}$ da porção superior, e três profundidades de plantio $(1,0 ; 5,0 ; 10,0 \mathrm{~cm})$ e cada parcela foi constituída de dez estacas com $20 \mathrm{~cm}$ de comprimento. Após 60 dias do plantio, foram iniciadas as avaliações semanais do número de brotações e aos 90 dias após o plantio foram avaliados sobrevivência, enraizamento, número e comprimento de brotações, massa seca das brotações, e massa seca das raízes. Os dados foram submetidos à análise de variância e à regressão polinomial a $5 \%$ de significância. $\mathrm{O}$ percentual de enraizamento e a sobrevivência das estacas usadas no experimento foi $100 \%$ em todos os tratamentos. Com o aumento da profundidade de plantio foi observado redução linear em: número de brotações, massa seca da parte aérea e a massa seca da raiz. Os cladódios com dominância apical obtiveram comprimento de brotações superior. O plantio de estacas de pitaia vermelha na profundidade de $1 \mathrm{~cm}$ e com dominância apical é mais satisfatório para a produção de mudas.
\end{abstract}

Palavras-chave: Hylocereus undatus, produção de mudas, propagação vegetativa

\begin{abstract}
This study was conducted to evaluate the effects of planting depth and breaking apical dominance on cutting of red pitaya Hylocereus undatus (Haw.) Britton \& Rose. The experiment was conducted in a randomized block design with four replications in a $2 \times 3$ factorial, with two kinds of cuttings (with or without apical dominance), cutting not sectioned and sectioned at $5 \mathrm{~cm}$ from the upper portion, and three planting depths $(1.0,5.0$, and $10.0 \mathrm{~cm})$ and each plot consisted of ten $20 \mathrm{~cm}$ long cuttings. After 60 days of planting, counts of the number of shoots were began weekly and 90 days after planting survival rooting, number and length of shoots, dry weight of shoots and root dry mass were evaluated. Data were subjected to analysis of variance and polynomial regression at 5\% significance level. The percentage of rooting and the survival were $100 \%$ in all treatments. With increasing depth of planting it was observed linear reduction in numbers of shoots, dry weight of shoot and root dry mass. The cladodes with apical dominance had longer shoots. The planting of red pitaya cuttings at $1 \mathrm{~cm}$ of planting depth with apical dominance is more suited to the production of nursery plants.
\end{abstract}

Key words: Hylocereus undatus, nursery plants production, vegetative propagation

\footnotetext{
${ }^{1}$ Doutorando(s) em Fitotecnia, Universidade Federal de Lavras, UFLA, Lavras, MG. E-mail: virnabm@hotmail.com; amatomoreira@yahoo.com.br

${ }^{2}$ Prof. do Dept ${ }^{\circ}$ de Agricultura, UFLA, Lavras, MG. E-mail: darlan@dag.ufla.br

${ }^{3}$ Discente do curso de Agronomia, UFLA, Lavras, MG. E-mail: neimararcanjo@yahoo.com.br

${ }^{4}$ Prof $^{\mathrm{a}}$. do Dept ${ }^{\mathrm{o}}$ de Agronomia, Universidade Federal dos Vales Jequitinhonha e Mucuri, UFVJM, Diamantina, MG. E-mail: mariceu@ufvjm.edu.br

* Autor para correspondência
} 


\section{Introdução}

A pitaia da espécie Hylocereus undatus (Haw.) Britton \& Rose é uma cactácea trepadeira, com caule classificado como cladódio, de formato triangular, pertencente ao grupo de frutíferas tropicais consideradas promissoras para o cultivo. Pois, atualmente ocupa um crescente nicho no mercado de frutas exóticas da Europa (LE BELLEC; VAILLANT; IMBERT, 2006) e é procurada no Brasil, não só pelo exotismo da aparência, como também por suas características organolépticas (SILVA; MARTINS; ANDRADE, 2006).

No entanto, as mudas comercializadas atualmente são desuniformes, promovendo em uma mesma área plantada variação do tamanho, formato e características físico-químicas dos frutos e da produção (JUNQUEIRA et al., 2010).

A formação de mudas uniformes pode ser obtida mediante a propagação vegetativa. O método utilizado para propagar a pitaia normalmente é a estaquia (BASTOS et al., 2006) por ser um processo de propagação assexuada desejável, principalmente pelo fato de as plantas originadas serem idênticas entre si e à planta-matriz (ANDRADE; OLIVEIRA; MARTINS, 2007; CARDOSO et al., 2011).

As informações e o entendimento sobre as técnicas de propagação vegetativa da pitaia relacionadas à profundidade de plantio são importantes, visto que a família Cactaceae é menos exigente em umidade e mais propícia ao apodrecimento com excesso de umidade, e a aplicação de métodos que propiciem o aproveitamento de cladódios seccionados ainda é incipiente.

Em outras espécies a ramificação das gemas é determinada pela dominância apical. A remoção da gema apical remove a fonte de dominância apical, estimulando o desenvolvimento das gemas axilares (CHEN et al., 1997), por promover o aumento de citocininas nas gemas laterais (ONO; GRANA JÚNIOR; RODRIGUES, 2004).
Pio et al. (2005) verificaram que a qualidade de mudas de marmeleiro está relacionado com a profundidade do plantio, pois quando as estacas foram plantadas em maior profundidade ficaram em maior contato com o substrato e dessa forma sofrem menor desidratação.

Esse trabalho foi conduzido com o objetivo de avaliar os efeitos da profundidade de plantio e da quebra da dominância apical na propagação vegetativa de pitaia vermelha.

\section{Material e Métodos}

O trabalho foi conduzido no período de setembro a dezembro de 2006 em telado coberto por sombrite com $50 \%$ de luminosidade, no setor de Fruticultura da Universidade Federal de Lavras em Lavras, MG. O tipo climático da região é $\mathrm{Cwb}$, segundo a classificação de Köppen, caracterizado com verões quentes e úmidos, e invernos secos e frios, e as variações de temperatura média, precipitação e umidade relativa foram registradas durante o período experimental na Figura 1.

O material utilizado foi coletado de plantasmatrizes sadias de pitaia vermelha, em plena produção, com 10 anos de idade. As estacas foram selecionadas a partir de cladódios maduros e sadios, cortadas com $20 \mathrm{~cm}$ de comprimento, aproximadamente. Metade das estacas foi seccionada a $5 \mathrm{~cm}$ da porção superior para a remoção da dominância apical. Após o corte, as estacas ficaram em galpão aberto nas laterais, com boa aeração, por 48 horas para cicatrização.

O experimento foi instalado no delineamento em blocos casualizados, com quatro repetições no esquema fatorial $2 \times 3$, sendo dois tipos de estacas (com e sem dominância apical) e três profundidades de plantio $(1,0 ; 5,0 ; 10,0 \mathrm{~cm})$ e cada parcela foi constituída de 10 estacas com $20 \mathrm{~cm}$ de comprimento. 
Figura 1. Médias mensais da temperatura $\left({ }^{\circ} \mathrm{C}\right)$, umidade relativa $(\%)$ e precipitação $(\mathrm{mm})$ durante o período experimental.

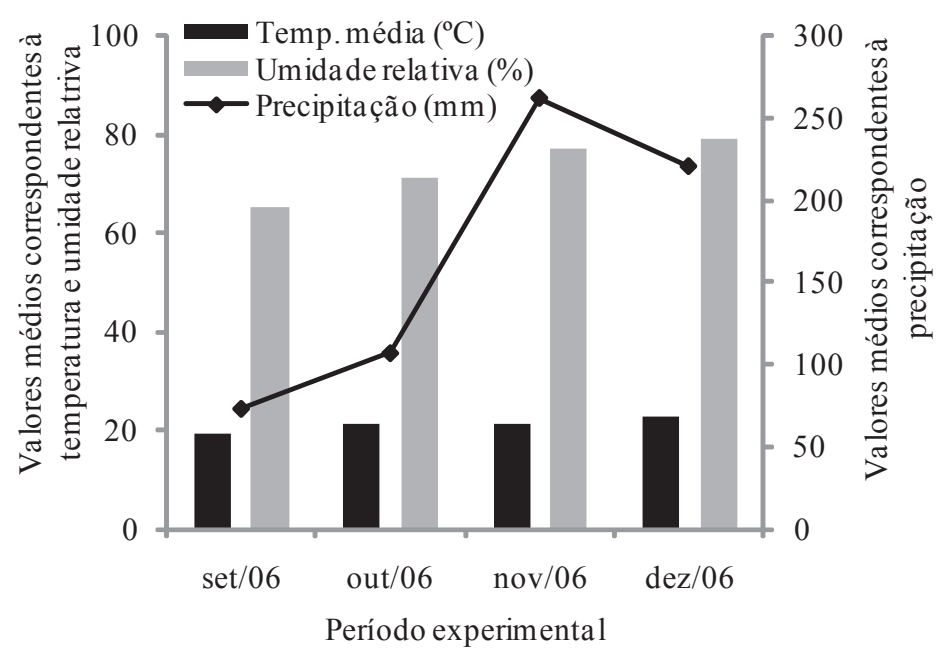

Fonte: Elaboração dos autores.

As estacas foram plantadas em sacos de polietileno preto perfurado com capacidade para 5 L, utilizando-se Latossolo Vermelho como substrato. O substrato utilizado apresentava as seguintes características: $\mathrm{pH} 6,1 ; 2,5 \mathrm{mg} \mathrm{dm}^{-3} \mathrm{de}$ P; $17 \mathrm{mg} \mathrm{dm}^{-3}$ de $\mathrm{K} ; 2,2$ Cmolc $\mathrm{dm}^{-3}$ de $\mathrm{Ca} ; 0,2$ Cmolc $\mathrm{dm}^{-3}$ de $\mathrm{Mg} ; 4 \%$ de $\mathrm{m} ; 48,4 \%$ de $\mathrm{V} ; 1,6 \%$ de matéria orgânica; $0,2 \mathrm{mg} \mathrm{dm}^{-3} \mathrm{de} \mathrm{B} ; 1 \mathrm{mg} \mathrm{dm}^{-3}$ de $\mathrm{Zn} ; 2,7 \mathrm{mg} \mathrm{dm}^{-3}$ de $\mathrm{Cu} ; 16,5 \mathrm{mg} \mathrm{dm}^{-3}$ de Fe; 16,1 $\mathrm{mg} \mathrm{dm}{ }^{-3} \mathrm{de} \mathrm{Mn} ; 5,8 \mathrm{mg} \mathrm{dm}^{-3} \mathrm{de} \mathrm{S}$. Durante o período de enraizamento a irrigação foi realizada sempre que necessária, deixando o substrato próximo da capacidade de campo.

Após 60 dias do plantio, foram iniciadas as contagens semanais do número de brotações. As avaliações referentes à sobrevivência (\%) e enraizamento (\%) das estacas, número e o comprimento de brotações (cm), massa seca das brotações ( $\mathrm{g}$ ) e massa seca das raízes ( $\mathrm{g}$ ) foram realizadas aos 90 dias após o plantio.

As brotações foram picadas para facilitar a secagem em estufa com circulação de ar forçada, em temperatura de $70{ }^{\circ} \mathrm{C}$ até a obtenção de massa constante, quando foram pesadas as amostras em balança de precisão. As raízes passaram por lavagem para retirar o substrato preso a elas, e posteriormente, também foram colocadas em estufa nas mesmas condições.

Os dados foram submetidos à análise de variância e à regressão polinomial a 5\% de significância.

\section{Resultados e Discussão}

Foi verificado $100 \%$ de enraizamento e sobrevivência em todos os tratamentos, semelhante ao obtido por Andrade, Oliveira e Martins (2007) e de Bastos et al. (2006) em estacas com o mesmo tamanho (97,9\%), ambos em sacos de polietileno sob ripado. Le Bellec, Vaillant e Imbert (2006), em estacas plantadas diretamente no campo, citam um percentual de $90 \%$ de enraizamento. $\mathrm{O}$ alto percentual de enraizamento demonstra a grande facilidade de enraizamento da espécie, possivelmente devido à relação carbono/nitrogênio, ao balanço hormonal de auxinas estarem adequados para o processo de formação de raízes nos cladódios (MARQUES et al., 2011a).

Para número de brotações foi observada interação entre a dominância apical e os níveis de profundidade de plantio, entre a dominância apical 
e as semanas de avaliação e entre as profundidades de plantio e as semanas de avaliação.

Com o aumento da profundidade de plantio foi observado redução linear do número de brotações para estacas com dominância e sem dominância apical (Figura 2A). Esse resultado pode ser atribuído ao maior contato das estacas ao substrato, que reduz a aeração podendo afetar a emissão de brotações (PIO et al., 2005).

Figura 2. Brotações de estacas de pitaia vermelha com (CD) e sem (SD) dominância apical: (A) número em função da profundidade de plantio e (B) número em função dos dias de avaliação.

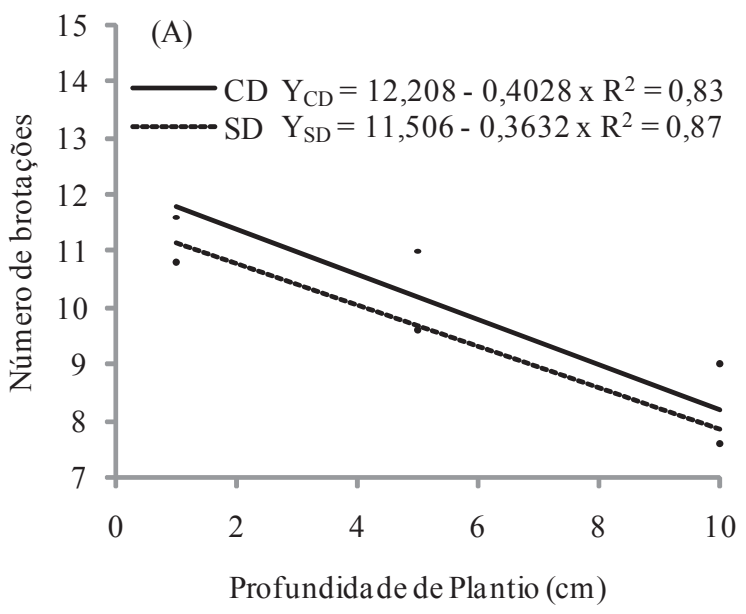

Fonte: Elaboração dos autores.

Em relação à avaliação realizada em função das épocas foi observado aumento na emissão de brotações das estacas com e sem dominância apical. Nas estacas sem dominância apical o número final de brotações emitido por estaca foi em torno de 13, com acréscimo semanal em torno de 2 brotações e nas estacas com dominância apical foi observado na avaliação final também cerca de 13 brotações por estaca, com aumento de aproximadamente 1 brotação a cada semana avaliada (Figura 2B). Isso demonstrou que o processo de cicatrização em estacas sem dominância apical apenas foi retardado no início da emissão de brotações, pois essas estacas apresentaram maior velocidade de emissão de brotações, alcançando aos 42 dias de avaliação o número de brotações das estacas com dominância. Ono, Grana Júnior e Rodrigues (2004) também observaram que a remoção da gema apical

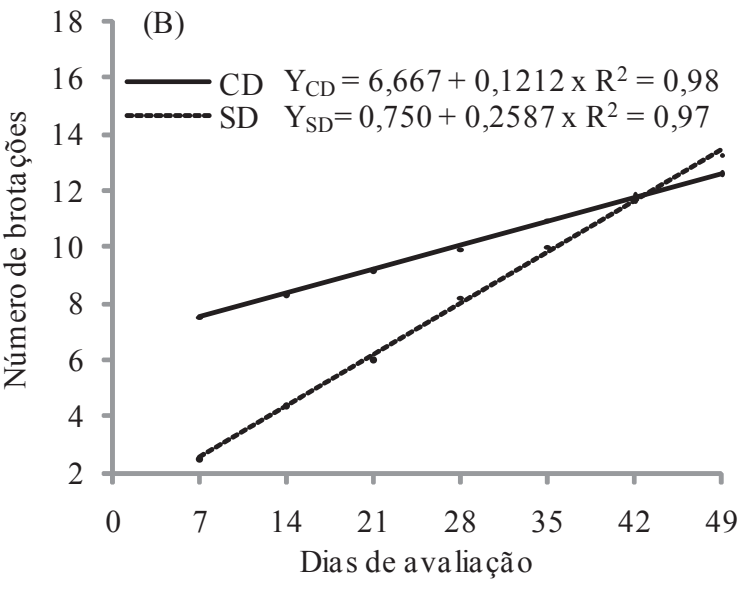

não induziu maior formação das brotações laterais em mamoeiro (Carica papaya L.).

Para o número de brotações nas estacas com e sem dominância observou-se aumento linear durante o período de avaliação em todas as profundidades de plantio (Figura 3). As mudas a $10 \mathrm{~cm}$ apresentaram menor número de brotações até o $32^{\circ}$ dia de avaliação, após esse dia observou-se maior número de brotações que as estacas plantadas a $1 \mathrm{~cm}$ de profundidade e ainda inferior às plantadas a $5 \mathrm{~cm}$. No final da avaliação ( $49^{\circ} \mathrm{dia}$ ) foram observados números de brotações semelhantes para estacas a 5 e a $10 \mathrm{~cm}$ de profundidade e menor número para estacas a $1 \mathrm{~cm}$. Este comportamento sugere que para as estacas colocadas em profundidade maior $(10 \mathrm{~cm})$ a emissão de brotações ocorre de forma lenta, quando comparada àquelas em profundidade menores. 
Verificou-se que as estacas plantadas em profundidade maior apresentaram menor comprimento de brotações. Estacas a $10 \mathrm{~cm}$ apresentaram tamanho de brotações 54,5\% menor, quando comparadas com estacas a $1 \mathrm{~cm}$ (Figura 4). Esse resultado pode ter ocorrido pela menor área fotossintética disponível fora do substrato em relação as que são plantadas a menores profundidades.
As estacas formadas por cladódios com dominância apical apresentaram comprimento de brotações superiores às que tiveram removida a dominância (Tabela 1). Este resultado indica que na propagação da pitaia vermelha o melhor desenvolvimento das mudas ocorre em estacas com a dominância apical, provavelmente por não ser necessário o gasto de energia com o processo de cicatrização.

Figura 3. Números de brotações em função dos dias de avaliação para estacas de pitaia vermelha plantadas a 1,5 e $10 \mathrm{~cm}$ de profundidade.

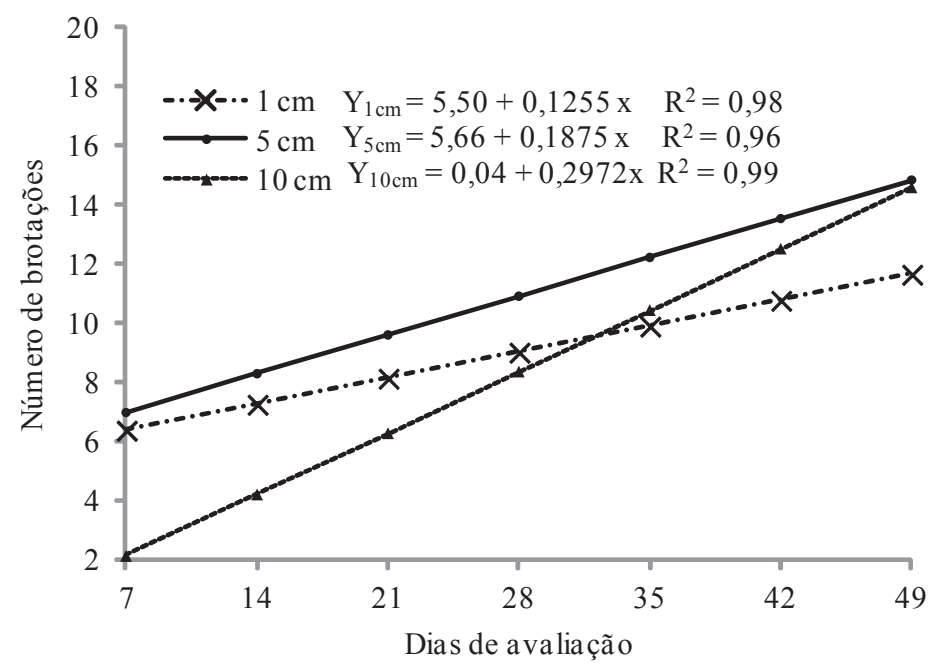

Fonte: Elaboração dos autores.

Figura 4. Comprimento de brotações em estacas de pitaia vermelha em função da profundidade de plantio.

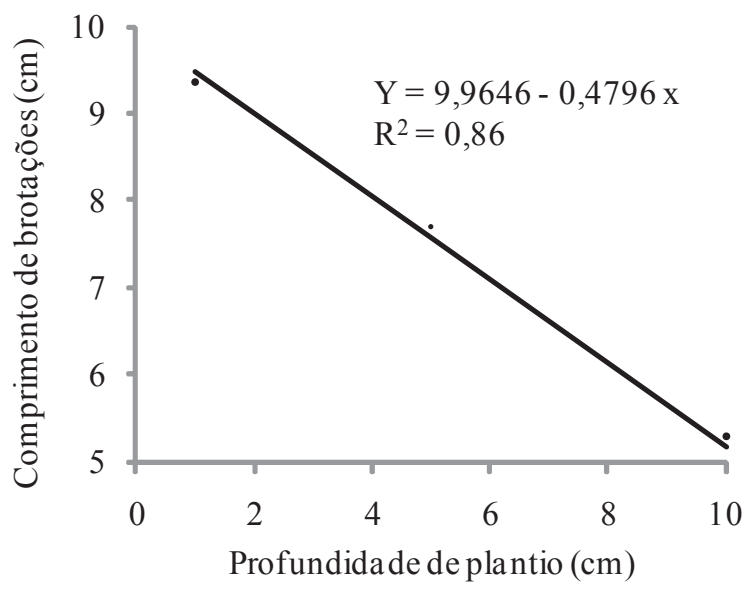

Fonte: Elaboração dos autores. 
Tabela 1. Comprimento das brotações de estacas com e sem dominância apical, avaliadas durante sete semanas, com início aos 60 dias do plantio.

\begin{tabular}{cc}
\hline Dominância Apical & Comprimento de brotações $(\mathrm{cm})$ \\
\hline Com dominância & 9,40 a \\
Sem dominância & $5,41 \mathrm{~b}$ \\
CV $(\%)$ & 25,8 \\
\hline
\end{tabular}

Médias seguidas de letras diferentes diferem estatisticamente pelo teste de $\mathrm{F}$ a $5 \%$ de probabilidade.

Fonte: Elaboração dos autores.

Em relação à massa seca da parte aérea e de raízes, as estacas plantadas nas profundidades de 5 e $10 \mathrm{~cm}$ apresentaram menores valores comparadas àquelas a $1 \mathrm{~cm}$. Nas estacas a $10 \mathrm{~cm}$ houve redução a 55,3\% na massa seca da parte aérea (Figura
$5 \mathrm{~A})$ e redução a $53,0 \%$ na massa seca de raízes (Figura 5B) em relação a estacas a $1 \mathrm{~cm}$. O menor desempenho das estacas plantadas a $10 \mathrm{~cm}$ pode estar relacionado com a redução de $50 \%$ da área fotossintética enterrada dentro do substrato.

Figura 5. (A) Massa seca da parte aérea (MSPA) (mg) e (B) massa seca da raiz (MSR) (mg) de estacas de pitaia vermelha função da profundidade de plantio $(\mathrm{cm})$.

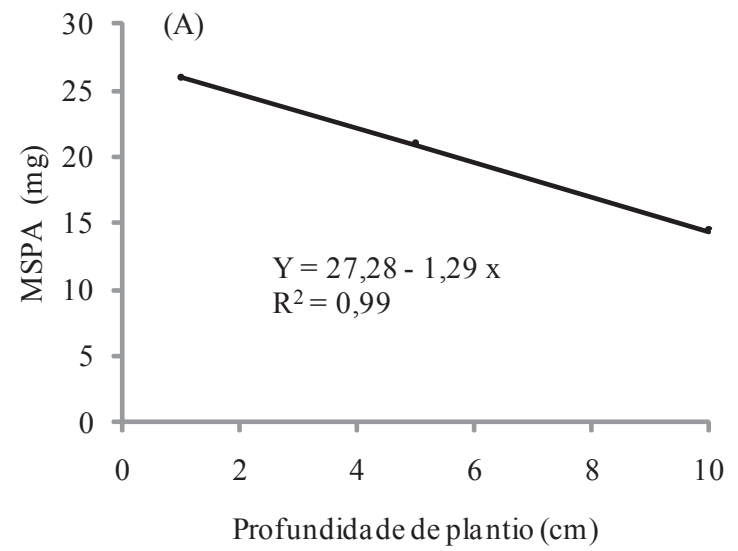

Fonte: Elaboração dos autores.

Vale ressaltar que as mudas enterradas a $1 \mathrm{~cm}$ permanecem firmes no substrato devido à morfologia triangular do cladódio facilitar sua fixação. Além disso, a emissão de maior quantidade de raízes e brotações compridas favorece o desenvolvimento das mudas, por facilitar no crescimento correto e da condução da planta no campo, que necessita ser tutorada (MARQUES et al., 2011b; MOREIRA et al., 2011a, 2011b), devido seu caule ser longo e frágil.

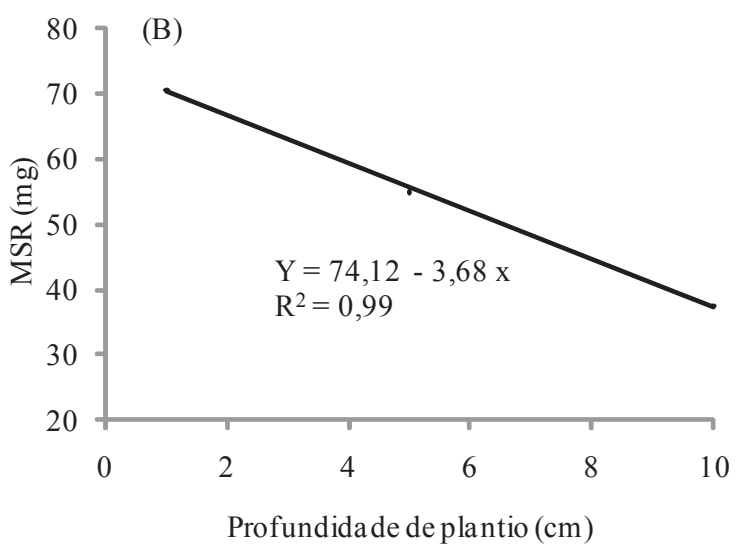

Outro aspecto que deve ser levado em conta é que na ausência de material propagativo os produtores podem usar a técnica de segmentação de cladódio para aumentar o número de mudas, pois dependendo do comprimento do cladódio podese conseguir mais de duas novas plantas. Porém, nesse caso ocorre um atraso inicial na emissão das brotações devido à cicatrização dos cortes, mas com o passar do tempo as mudas podem se recuperar. 


\section{Conclusões}

O plantio de estacas de pitaia vermelha na profundidade de plantio de $1 \mathrm{~cm}$ e com dominância apical é mais satisfatório para a produção de mudas.

\section{Referências}

ANDRADE, R. A. de; OLIVEIRA, I. V. de M.; MARTINS, A. B. do. Influência da fonte e do tempo de cura na propagação vegetativa da pitaya vermelha. Revista Brasileira de Fruticultura, Jaboticabal, v. 29, n. 1, p. 183-186, 2007.

BASTOS, D. C.; PIO, R.; SCARPARE FILHO, J. A.; LIBARDI, M. N.; ALMEIDA, L. F. P.; GALUCHI, T. P. D.; BAKKER, S. T. Propagação da pitaya 'vermelha' por estaquia. Ciência e Agrotecnologia, Lavras, v. 30, n. 6, p. 1106-1109, 2006.

CARDOSO, C.; YAMAMOTO, L. Y.; PRETI, E. A.; ASSIS, A. M.; NEVES, C. S. V. J.; ROBERTO, S. R. AIB e substratos no enraizamento de estacas de pessegueiro 'Okinawa' coletadas no outono. Semina: Ciências Agrárias, Londrina, v. 32, n. 4, p. 1307-1314, 2011.

CHEN, J. G.; ZHAO, H. Y.; ZHOU, X.; MAO, L. S.; CHEN, X. X. Flutuation in levels of endogenous hormones after decapitation and 6-benzyl amino purine treatement in azalea, and their relationship to apical dominance. Scientia Horticulturae, Amsterdam, v. 71, n. 1, p. 49-58, 1997.

JUNQUEIRA, K. P.; FALEIRO, F. G.; BELLON, G.; JUNQUEIRA, N. T. V.; FONSECA, K. G.; LIMA, C. A.; SANTOS, E. C. Variabilidade genética de acessos de pitaya com diferentes níveis de produção por meio de marcadores RAPD. Revista Brasileira de Fruticultura, Jaboticabal, v. 32, n. 3, p. 840-846, 2010.
LE BELLEC, F.; VAILLANT, F.; IMBERT, E. Pitahaya (Hylocereus spp.): a new crop, a market with a future. Fruits, France, v. 61, n. 4, p. 237-250, 2006.

MARQUES, V. B.; MOREIRA, R. A.; RAMOS, J. D.; ARAÚJO, N. A.; CRUZ, M. C. M. Tamanho de cladódios na produção de mudas de pitaia vermelha. Revista Caatinga, Mossoró, v. 24, n. 4, p. 50-54, 2011 a.

MARQUES, V. B.; MOREIRA, R. A.; RAMOS, J. D.; ARAÚJO, N. A.; SILVA, F. O. R. Fenologia reprodutiva de pitaia vermelha no município de Lavras, MG. Ciência Rural, Santa Maria, v. 41, n. 6, p. 984-987, 2011 b.

MOREIRA, R. A.; RAMOS, J. D.; ARAÚJO, N. A.; MARQUES, V. B. Produção e qualidade de frutos de pitaia-vermelha com adubação orgânica e granulado bioclástico. Revista Brasileira de Fruticultura, Jaboticabal, v. 33, p. 762-766, 2011b. Especial.

MOREIRA, R. A.; RAMOS, J. D.; MARQUES, V. B.; ARAÚJO, N. A.; MELO, P. C. Crescimento de pitaia vermelha com adubação orgânica e granulado bioclástico. Ciência Rural, Santa Maria, v. 41, n. 5, p. 785-788, 2011a.

ONO, E. O.; GRANA JÚNIOR, J. F.; RODRIGUES, J. D. Reguladores vegetais na quebra da dominância apical de mamoeiro (Carica papaya L.). Revista Brasileira de Fruticultura, Jaboticabal, v. 26, n. 2, p. 348-350, 2004.

PIO, R.; RAMOS, J. D.; CHALFUN, N. N. J.; GONTIJO, T. C. A.; CARRIJO, E. P.; MENDONÇA, V.; ALVARENGA, Q. A.; ABRAHÃO, E. Enraizamento de estacas dos marmeleiros 'Portugal' e 'Japonês' em diferentes ambientes e posições no recipiente. Ciência e Agrotecnologia, Lavras, v. 29, n. 5, p. 968-973, 2005.

SILVA, M. T. H.; MARTINS, A. B. G.; ANDRADE, R. A. Enraizamento de estacas de pitaya vermelha em diferentes substratos. Revista Caatinga, Mossoró, v. 19, n. 1, p. 61-64, 2006. 
